\title{
Hipólito antes do Correio: um repórter autodidata
}

\author{
Paulo Roberto de Almeida
}

\section{Resumo}

Lido à distância de mais de dois séculos, não tanto pela sua forma, mas pelo seu conteúdo efetivo, as anotações e observações de Hipólito da Costa em seu Diário de Viagem, em que relata sua viagem aos Estados Unidos, adquirem um caráter de ensaio sociológico avant la lettre, possuindo todos os requisitos literários para figurar como obra fundadora do americanismo brasileiro, e quiçá universal. Seu diário é uma grande reportagem com desconcertantes antecipações sobre a sociedade americana e que confirma, também por antecipação, a densidade analítica e o gênio de "escrevinhador" do futuro jornalista (aliás, único) do Correio Braziliense.

Palauras-chave:

Hipólito da Costa, Diário de Viagem, Americanismo, Jornalismo, Correio Braziliense

\section{Hipólito before the Correio Braziliense: a self-taught reporter}

\section{Abstract}

\section{Sobre o autor}

Doutor em Ciências Sociais pela Universidade de Bruxelas, é diplomata de carreira, professor no Mestrado em Direito do Centro Universitário de Brasília (Uniceub) $e$ professor orientador do Mestrado em Diplomacia do Instituto Rio Branco do Itamaraty. Cursa pósdoutorado na Pontifícia Universidade Católica do Rio de Janeiro - PUC-RJ. pralmeida@mac.com
Read with the distance of two centuries, not because of its manner, but for its efective content, Hipolito da Costa's notes and observations in his Diário de Viagem, in which he reports his trip to the United States, acquires characteristiscs of a sociologic essay avant la lettre. It presents all literary requisits to figure as the founding work of brazilian americanism. His diary is a long story with amazing anticipations on American society, and confirms, also on anticipation, the analitic density and the writer genius of Correio Braziliense's future (and only) journalist.

Keywords:

Hipólito da Costa, Diário de Viagem, Americanism, Journalism, Correio Braziliense 


\section{Jornalista malgré-lui}

Grandes jornalistas começam, usualmente, como repórteres iniciantes. Não foi diferente com Hipólito José da Costa Pereira Furtado de Mendonça. Seu aprendizado profissional se deu, não na redação de jornais ou de folhas literárias, mas no terreno da prática, como também ocorre com os melhores jornalistas. De toda forma, mesmo que ele desejasse fazê-lo, não poderia: simplesmente não existiam pasquins independentes, nem em sua terra de infância, os pampas sulinos, nem em Portugal, onde completou sua formação acadêmica. Tanto Portugal, como o Brasil eram extremamente acanhados em matéria de veículos de imprensa, premidos ambos, metrópole e colônia, por um ambiente sufocante, opressivo, dominado pela pieguice integrista das elites reacionárias, vigiadas de perto por um clero contra-reformista e, obviamente, anti-iluminista. Não havia espaço para sequer um tipo tênue de "jornalismo independente" em qualquer lado do Atlântico.

Por um desses curiosos acasos da história, Hipólito praticou, como aprendiz, uma espécie de "jornalismo independente", não em uma de suas duas pátrias, mas em terra estrangeira, aliás, na pátria da liberdade de imprensa. Seu primeiro grande trabalho de "reportagem", antes de se estabelecer na Inglaterra, fugindo da Inquisição portuguesa, e de ali editar por quase três lustros o Correio Braziliense, começou por uma missão de prospecção econômica, como "enviado especial ao exterior", para usar a linguagem do jornalismo atual. Suas instruções compreendiam uma descrição detalhada dos progressos feitos pelos Estados Unidos nos campos da agricultura, das manufaturas, das ciências e das artes e ofícios, enfim, um relatório econômico completo, sem esquecer um pouco de espionagem industrial, no campo da produção têxtil.

\section{A missão}

Sua "missão" investigativa à jovem nação recentemente independente foi, sem dúvida, encomendada, mas a "reportagem" preparada por Hipólito foi inteiramente elaborada segundo sua própria intuição, baseada numa percepção peculiar do que ele considerou relevante para informação daquele que o tinha enviado em “missão especial”, D. Rodrigo de Souza Coutinho, então ministro da Fazenda em Portugal e futuro ministro dos Negócios Estrangeiros do príncipe regente, D. João, na vinda para o Brasil. Grande estadista português da transição para o século XIX, D. Rodrigo ostentava uma concepção econômica da administração pública, preocupando-se com a agricultura, o comércio, a gestão financeira e as práticas industriais. Foi ele, provavelmente, quem inculcou no jovem Hipólito o gosto pelas questões econômicas,

Por um desses
curiosos acasos
da história,
Hipólito praticou,
como aprendiz,
uma espécie
de "jornalismo
independente",
não em uma de
suas duas pátrias,
mas em terra
estrangeira

Por um desses curiosos acasos da história, Hipólito praticou, como aprendiz, uma espécie de "jornalismo independente", não em uma de mas em terra estrangeira 
inclinação que este manteve durante toda a sua vida, aliás revelada de maneira cabal nas páginas do seu "armazém literário".

Recém formado em direito em meados de 1798, Hipólito recebeu do futuro conde de Linhares, menos de três meses depois, o encargo de fazer no território da América do Norte (Estados Unidos e México) o que se poderia designar, na moderna linguagem dos negócios, de comissão de prospecção econômica. O jovem advogado (24 anos) deveria elaborar um relatório específico e detalhado sobre suas observações agrícolas, industriais e botânicas nos Estados Unidos. Ele estava preparado para esse tipo de missão. Graças a um tio sacerdote - o padre Pedro Pereira Fernandes de Mesquita, que tinha conhecido D. Rodrigo Coutinho, quando de uma estada em Lisboa - o adolescente Hipólito tinha recebido uma instrução clássica e humanista em Porto Alegre, depois complementada por uma formação em botânica e ciências naturais, quando de sua estada na Universidade de Coimbra, primeiro na Faculdade de Filosofia e Matemática, antes de ser admitido na de Leis, em outubro de 1793.

Ao partir para os Estados Unidos, no final de 1798, Hipólito provavelmente não pretendia se tornar jornalista, "profissão" que ele assumiu involuntariamente mais tarde, ao lhe serem fechadas as possibilidades de trabalho (e de vida) em Portugal. Mas ele tinha, incontestavelmente, o dom da escrita. Na verdade, a missão nos Estados Unidos comportava um caráter sobretudo técnico, mais do que de prospecção de mercados ou de incentivo ao comércio. Tratava-se de levantar os recursos naturais e apreciar os conhecimentos científicos que a jovem nação independente da América do Norte mobilizava em sua marcha ascensional para o progresso econômico.

Em outros termos, o encargo comportava também aspectos que hoje em dia poderiam ser equiparados à "espionagem industrial ou tecnológica”, numa etapa histórica na qual os direitos de propriedade intelectual não desfrutavam da mesma proteção absoluta como na atualidade. O futuro "pai da imprensa" brasileira estava amplamente habilitado para fazê-lo, uma vez que, ademais dos conhecimentos práticos aprendidos em sua vida de fazenda no Rio Grande, ele tinha sido formado em outras matérias que apenas filosofia e direito. Os estudos de filosofia em Coimbra comportavam, precisamente, o ensino de botânica, agricultura, zoologia, mineralogia, física, química e mineralogia, artes e disciplinas nas quais também tinha se destacado o futuro "pai da independência”, José Bonifácio, freqüentador das academias européias.

\section{Nos Estados Unidos}

Quando Hipólito partiu para os Estados Unidos e o México, no final de 1798, ele era, portanto, um recém formado, pronto para 
completar a sua formação no terreno, uma espécie de "mestrado" em missão de trabalho. As instruções de Coutinho eram no sentido de se obter informações as mais detalhadas possíveis sobre todos os progressos havidos na América do Norte no terrenos das artes práticas, das culturas agrícolas e dos ofícios ligados ao fabrico e manufatura de bens em geral, complementando a missão pelo encargo de recolher as espécimes e variedades de plantas e cultivos que se pudessem aproveitar em Portugal e na colônia brasileira.

Atenção especial deveria ser dada ao cultivo do tabaco, então concentrado em Maryland e na Virgínia, ao passo que no México, ademais de observar as minas de ouro e prata, a instrução essencial era a de lograr subtrair o inseto e a planta da cochonilha, iludindo a vigilância rigorosa das alfândegas espanholas. De tudo, Hipólito deveria mandar relatórios circunstanciados, o que ele obviamente fez de maneira rigorosa, ao despachar notícias teóricas e comentários práticos sobre tudo o que viu e ouviu em sua longa estada naquelas partes, nos anos finais do século XVIII (Costa, t.31, 1858: 352-363) ${ }^{1}$.

Nos Estados Unidos, Hipólito teve de, algumas vezes, fazer-se de diplomata, mesmo sem autorização para tanto ou diploma legal, por motivo da ausência do representante português, ministro Cipriano Ribeiro Freire. Mais importante do que esse exercício episódico de diplomacia, de fato mais bem em encargos consulares, foi a provável adesão de Hipólito, nessa estada, à maçonaria, possivelmente mais relevante na determinação de seu futuro destino político do que a missão de "espionagem industrial" pela qual iniciava sua vida profissional. Em todo caso, sua prospecção técnicocientífica na América do Norte poderia ser também aproximada de uma missão de diplomacia econômica, não no sentido negociador, mas no de uma "embaixada" voltada para a informação a mais ampla possível sobre as capacidades naturais e os atributos humanos de uma potência amiga, como forma de habilitar a sua pátria (e a sua terra de formação) a competirem em melhores condições no grande jogo econômico das indústrias e do comércio que Linhares adivinha formavam a base da potência das nações.

Paralelamente às anotações que compunha para o seu relatório oficial, Hipólito manteve, durante todo o período de estada na costa leste dos Estados Unidos, um diário de viagem, no qual consignou suas observações pessoais sobre os encontros, conversas e cenas assistidas durante os quinze meses da missão. Esse Diário de Minha Viagem para Filadélfia, 1798-1799, ficou inédito durante um século e meio, tendo sido encontrado na Biblioteca de Évora por Alceu Amoroso Lima, que o fez anotar e publicar pela Academia Brasileira de Letras em $1955^{2}$. Não destinado à publicação, mas sumamente adaptado ao formato do ensaio bem informado, o Diário de Hipólito pode ser comparado, sem nenhum deslustro, a uma espécie de viagem filosófica,

${ }^{1} \mathrm{Na}$ verdade, Hipólito não conseguiu viajar para o México, tanto por falta de navios quanto de visto apropriado, sem mencionar a falta de dinheiro, tendo embarcado de volta a Portugal a partir de Filadélfia, no segundo semestre de 1800. Seu relatório foi feito seis meses depois, conforme a última anotação do seu diário: "A memória que relata os progressos e resultados da minha comissão foi datada de 24 de janeiro de 1801 , e a pretendo entregar a S.Exa. o Ministro da Fazenda, juntamente com a tradução da História do Banco da Inglaterra que me mandou fazer, amanhã, quinta-feira, 5 de fevereiro".

${ }^{2}$ As edições do Diário de Minha Viagem para Filadélfia, 1798-1799, de Hipólito José Costa Pereira, foram as seguintes, no Brasil: Rio de Janeiro: Publicações da Academia Brasileira, 1955; Porto Alegre: Sulina Editora, 1974; Brasília: Senado Federal, 2004. Em Portugal, a primeira edição, anotada por Alcino Pedrosa, saiu pelo Instituto de Ciências Sociais da Universidade de Lisboa, em 2007, com uma preciosa introdução e uma bem cuidada pesquisa historiográfica pelo seu organizador. 
que ainda hoje surpreende pela pertinência e acuidade das observações sociológicas, bem como pela atualidade dos seus julgamentos certeiros, a começar pelos seus comentários pertinentes em torno dos hábitos e características da população americana (em grande parte emigrada), da proliferação da "indústria religiosa" naquele país (et pour cause) e também pelas observações mordazes feitas a propósito da "rusticidade" de sua classe dirigente.

\title{
Os "modos" americanos
}

Nessa missão Hipólito conheceu artesãos, cientistas e agricultores, ademais do futuro, Thomas Jefferson, e do então presidente dos Estados Unidos, John Adams, cuja informalidade e falta de protocolo surpreenderam um pouco o súdito de uma monarquia absoluta, rigorosa com o cerimonial:

O Presidente [John Adams] estava de pé, de casaca, espada e chapéu debaixo do braço, conversando com algumas pessoas que ali se achavam. Quando se entra, dirige-se a ele e se lhe faz um cumprimento; ele pega na mão, pergunta pela saúde e diz mais alguma coisa; a mim me perguntou que tal achava o seu país; depois disto, todas as pessoas conversam uma com as outras, mesmo, passeiam pela casa e o mesmo Presidente muda de lugar freqüentemente, de modo que estão todos confundidos sem ordem ou arranjamento de etiqueta. Os Senadores e pessoas mais qualificadas que entraram, vinham uns de botas, outros sem pós nos cabelos, casacas velhas, quase todos, vieram a pé a maior parte; de sorte que, à exceção dos ministros estrangeiros, todo o resto respirava muito pouca civilização de maneiras polidas; à saída, não se lhe fez [ao Presidente] outro cumprimento, que uma vênia com a cabeça, a que ele correspondeu igualmente. (1o de janeiro de 1799)

No mesmo mês, ele foi a uma festa, à qual compareceu o Presidente, e continua a se espantar com a falta de cerimonial:

\begin{abstract}
Hoje à noite (16), fui a um baile que se fez em honra do Presidente, no teatro da cidade. [...] O Presidente ficou sentado em um camarote onde havia senhoras (mas não a sua nem outra que lhe pertencesse) e as tinha por trás de si. Quando foram para a ceia, ele foi levado pela mão, pelo mestre de cerimônia, como se fora senhora. As mesas, à ceia, não tinham criados para servir, não tinham pratos para se mudar; não havia facas e garfos senão de ferro; não se mudavam nem lavavam. [...] As gazetas atestam que é a maior função que aqui se tem feito, o que me dá a entender que nunca nos Estados Unidos se viu uma função brilhante.
\end{abstract}

Suas observações sobre as mulheres não deixam de fazer graça, pelo inusitado das comparações:

Estudos em Jornalismo e Mídia - Ano V - n. 2 pp. XX - XX jul./ dez. 2008 
As mulheres em New York são mais bonitas que em Filadélfia, tendo geralmente bons dentes, o que é raro entre as filadelfianas; porém são muito mais desengraçadas, passeiam com as pontas dos pés para diante, com longas passadas, e, depressa, ordinariamente, o que faz as saias baterem por as pernas com uma muito má figura; os braços vão ordinariamente caídos como mortos, ou um suspende a cauda do vestido, mas isto do modo o mais desengraçado possível. Se as senhoras de Lisboa fossem a metade tão linda como são as iorquenses, com o seu garboso, seriam uma perfeitas belezas, mas a natureza divide estes dons para os equilibrar. (30 de julho de 1799).

\section{Preocupações sanitárias e agrícolas}

Numa era de poucos conhecimentos científicos sobre a conservação e a sanidade dos alimentos, Hipólito faz suas próprias experiências:

Hoje [21 de janeiro de 1799], pelas 10 horas, enchi uma garrafa de água da bomba para experimentar quanto tempo dura até se corromper. Um sujeito me disse que, no tempo de Verão, tinha deixado um copo de água a descoberto, por uma noite; ao outro dia, tinha evaporado uma terça parte e o resto tinha a consistência de geléia mole, com um grande sedimento de cor amarela e fétida.

A curiosidade por novas técnicas agrícolas estava sempre presente:

Hoje [6 de fevereiro], estive na casa do ministro da Espanha, que me disse algumas coisas sobre ciências naturais; assegurou-me que a agricultura nos Estados do Norte, e no Canadá, estava em muito melhor pé que nos Estados do Sul; mostrou-me uma espécie de charrua inventada por Mr. Jefferson [a quem ele conheceria pouco depois na casa do mesmo diplomata] e mostrou-me em um armário 193 espécies de madeira das Filipinas; disse-me que Mr. Jefferson tinha trazido para a Virgínia perto de 20 variedades de arroz.

Hipólito despacha freqüentemente caixas de sementes a D. Rodrigo, por intermédio do ministro de Portugal, cumprindo com as instruções daquele: seu diário tem muitas listas de plantas, identificadas pelo seu nome científico.

Seu "diário de viagem" não é uma simples coleção de observações naturalistas e agrícolas, pois Hipólito tece considerações extensas sobre as religiões dos americanos e, mais importante, sobre questões econômicas e monetárias. Não deixou de notar a preferência dos americanos pelo comércio, mais que pela agricultura, e o seu gosto acentuado pela especulação, sendo o dinheiro um valor absoluto naquela sociedade.
Hipólito tece considerações extensas sobre as religiões dos americanos e, mais importante, sobre questões econômicas e monetárias 


\title{
As primeiras crises financeiras
}

Já naquela época, os bancos emprestavam facilmente, acima das posses reais, animando os empreendimentos e facilitando as especulações mercantis, muito embora no interior do país a falta de dinheiro condenasse os produtores muitas vezes ao escambo. Ele observou, também, as tendências a falências abruptas e a uma mobilidade excepcional nos negócios, traços que ainda hoje marcam a modalidade peculiar do capitalismo americano. Hipólito escreveu isto em seu diário, em junho e julho de 1799:

\begin{abstract}
Nos Estados Unidos, os bancos dão mais dinheiro imaginário, fazem os particulares empreenderem além das suas posses reais; eis porque há tantas rôtas [falências] e quebras. [...] Uma prova da pobreza das famílias nos Estados Unidos é a grande quantidade de boardings e lodgings... quase todas as casas admitem gente para morar e comer por uma certa paga; ora, isso não aconteceria se eles tivessem dinheiro. [...] Outra prova da pobreza desta terra é que as rendas [impostos] são pagas quase todas em frutos [produtos]..." (4 e 12 de junho de 1799).
\end{abstract}

Em nota a este parágrafo, Hipólito esclarece: "O juro ordinário é de 2 por 100 no mês, não é raro 3, e algumas vezes mais. As gazetas de tantos de Julho se queixavam que os usurários estragavam o comércio e arruinavam os negociantes levando continuamente o juro de 5 por cento cada mês".

Indubitavelmente, o comércio dos Estados Unidos é demasiado, não sendo por nenhum modo proporcionado à agricultura e [à] produção do país. [O] resultado é que eles têm desprezado a agricultura, e empregado-se de tal modo ao comércio, que é a paixão dominante; a especulação é o espírito público; o dinheiro é a única virtude que ambicionam. (14 de julho de 1799)

Como se vê, nada de muito novo em termos de funcionamento do sistema econômico, particularmente no que toca a "infectious greed" (apud e copyright Alan Greenspan) que não parece ter contaminado apenas recentemente os executivos das empresas americanos.

\section{A potência em formação, e seus problemas básicos}

Os Estados Unidos do final do século XVIII estavam obviamente longe de se constituírem em uma sociedade industrial e, de fato, eles se tornaram a primeira potência econômica do planeta apenas no final do século XIX, quando ultrapassaram o volume da produção industrial combinada da Grã-Bretanha e da Alemanha. Naquela conjuntura, os fluxos de comércio, as inovações técnicas e as finanças internacionais ainda eram dominados pelos países mais avançados da Europa, mas o "modo inventivo" ameri-

Estudos em Jornalismo e Mídia - Ano V - n. 2 pp. XX - XX jul./ dez. 2008 
cano já exibia todas as características sociais e financeiras que converteriam o país de uma sociedade agrária em potência industrial.

Ainda que não descritas com tal estilo "sociológico" em seu diário de viagem, essas características empíricas da sociedade americana - mais do que qualquer teoria econômica ou doutrina comercial, das quais os EUA continuariam, aliás, sendo importadores líquidos pelo resto do século XIX - devem ter impressionado a mente do jovem Hipólito, determinando muito de suas reflexões pragmáticas posteriores sobre os problemas econômicos, comerciais e monetários "brazilienses".

A despeito de todo o progresso que contemplou, Hipólito testemunhou problemas típicos de uma sociedade em formação, como os ataques de febre amarela durante o verão. Em pleno mês de agosto de 1799, ele relatava de Filadélfia: "Há quatro dias que está o tempo chuvoso e tão frio como no Inverno em Portugal. A febre amarela tem principiado aqui as suas destruições já, e a gente começa a mudar-se para o campo" (dia 19). "A febre tem se mostrado horrorosa nestes dois dias, e o povo começa a desamparar a cidade, e eu, se não parto já, é porque não posso..." (22). "Hoje, a minha hospedeira deixou a cidade e fui para outra casa, mas ela era tão suspeita que não pude estar lá mais que um dia" (23). "Hoje me mudei para outra casa e como a mulher está quase indo para o campo, brevemente me tornarei a mudar" (24).

Mesmo em Nova York, a situação não era melhor, conforme ele tinha escrito pouco antes de começar o verão:

A estação principia a ser muito calmosa, e tudo anuncia a torna da febre amarela este Verão. O Ministro de Inglaterra partiu para o Canadá, onde pensa passar o Verão e, na capital dos Estados Unidos só estão aqueles oficiais do governo, que têm uma imediata necessidade de aí residir. O mesmo Presidente está em Massachusetts (carta de 15 de junho de 1799 a D. Rodrigo de Sousa Coutinho).

Em setembro ele relatava ao ministro que "a febre amarela continua a assolar este país”, fazendo então o relato das muitas mortes que se tinham produzido na Filadélfia.

\section{Sem visto para o México}

Um dos principais objetivos da viagem de Hipólito à América do Norte era o de passar dos Estados Unidos ao México, para aí obter, pelos meios possíveis, o inseto e a planta da cochonilha, que serviam para a indústria têxtil. Sua passagem para o México, supondose que obtivesse o visto necessário do ministro espanhol em Filadélfia, teria de ser feita, conforme explicou a D. Rodrigo, através de Havana e daí a Vera Cruz, "duas viagens assaz dispendiosas". "A primeira dificuldade", explicava ele em carta de 24 de março de
Essas características empíricas da sociedade americana devem ter impressionado a mente do jovem Hipólito, determinando muito de suas reflexões pragmáticas posteriores 
é poder exportar de Vera Cruz para Havana a planta e inseto sem que seja percebido, porque tal exportação é proibida debaixo de grandes penas; mas espero que, por meio de indústria e dinheiros, ela se possa conseguir e escapar ainda ao outro perigo de sair de Havana. Encontro, porém, uma maior dificuldade na sua condução, porque a planta, que é de uma natureza muito diversa daquele que temos no Brasil, (...) e muito menos os insetos poderão sofrer as mudanças e alternativas do clima, vindo de Vera Cruz para Havana, dali para Filadélfia ou Nova York, daqui para Lisboa e de Lisboa para o Brasil, sendo impossível que depois de todas essas viagens o inseto possa estar vivo. O único meio que lembro para vencer esta dificuldade será esperar algum navio que vá dos Estados Unidos com escala para o Brasil, e fazer passar nele a planta, no caso de se poder obter de Havana.

Ele continuava sua carta ao ministro da Fazenda, registrando o obstáculo que representava a política de exclusivo colonial português, com o cerceamento completo de qualquer contato entre a colônia e terceiras partes que não fosse por intermédio de Lisboa e com a devida autorização real:

Suponho que são raros os exemplos de ter S. Majestade dado licença a navios que vão daqui para o Brasil, mas a ser possível conceder-se neste caso, teríamos a vantagem de poder ali introduzir muitas plantas utilíssimas, e principalmente a que vou dizer a V.Excia., talvez mais interessante para nós, que a mesma cochonilha, e é uma nova espécie de cana-de-açúcar que foi trazida da ilha Otahito, e que me não parece estar inda descrita por algum botânico. Esta cana... rende o duplo da outra, e um francês, antigo habitante de S. Domingos, me assegurou que, tendo obtido esta cana, viu que lhe rendia o triplo da outra, e que o açúcar era de melhor qualidade, tendo alem disto a vantagem de que o bagaço depois de seco abunda para o fogo, necessário na depuração de toda a calda que a mesma cana tem produzido.

Não tendo obtido visto nem recursos adicionais, ainda assim Hipólito cogitava de algum modo cumprir sua missão, como expôs em carta de 15 de abril de 1799 ao mesmo D. Rodrigo:

o Ministro de Espanha disse que tinha recebido ordens modernas de sua corte para não deixar ir algum estrangeiro qualquer a Vera Cruz; (...) eu concluo da mudança e hesitação das suas respostas, falta de sinceridade que me é suspeita, e que porquanto me seria mais fácil ir disfarçado, mudando o nome, fazendo-me espanhol e metendo-me a bordo de algum navio com qualquer emprego nele, do que ir com cartas deste Ministro que me fariam mais visível e os disporia talvez a acautelarem-se mais a meu respeito.
Não tendo obtido visto nem recursos adicionais, ainda assim Hipólito cogitava de algum modo cumprir sua missão 
Infelizmente, todas essas cogitações de Hipólito, que dependiam de apoio financeiro de Lisboa para poderem ser concretizadas, nunca vieram a se realizar.

Em agosto desse ano, porém, ele relatava em carta que tinha recebido várias plantas, entre elas a árvore do pão, a nova canade-açúcar e a planta e o inseto da cochonilha:

O prazer que tive em alcançá-las foi igual ao trabalho de obtê-las, e as vivas recomendações de V.Excia. sobre a última, mas não é menos o desassossego em que estou sobre o modo de conservá-las." Ele tomou a resolução de "esperar as ordens" do ministro (carta de New Brunswick, em 15 de agosto de 1799). Foi, entretanto, com enorme tristeza que Hipólito informava em dezembro que "o frio e neve que caiu nos dias 18 , 19 e 20 de Novembro não só matou o inseto e destruiu totalmente as árvores do pão, mas arruinou quase todas as outras plantas, à exceção do cactus... (carta de Filadélfia, de 3 de dezembro de 1799).

Em 3 de fevereiro seguinte, ele apresentava ao ministro a conta das despesas que lhe tinham sido obrigatórias para mandar vir as plantas descritas, na altura de 381 dólares, ou - à razão de 800 réis por dólar - exatamente $304 \$ 848$.

$\mathrm{Um}$ dos objetivos principais de sua viagem permaneceu inconcluso, portanto, mas não por falta de vontade e disposição do jovem Hipólito de persegui-los e de empreender a viagem em quaisquer circunstâncias, como demonstrado em suas cartas. Em seu diário e em toda a sua correspondência ele demonstra sua preocupação em trazer para a colônia lusitana da América as espécies vegetais e animais e os melhoramentos técnicos que julgava poderiam contribuir para o engrandecimento de sua pátria de fato.

\section{O jornalista aprendiz}

Lido à distância de mais de dois séculos, não tanto pela sua forma, mas pelo seu conteúdo efetivo, o Diário de Viagem de Hipólito sustenta muito bem a comparação com o bem mais cuidadosamente elaborado ensaio de Tocqueville sobre os Estados Unidos, este, sim, feito para expor aos franceses os contornos sociais e políticos do imenso laboratório humano e social que então constituía a América do Norte. Justamente por não pretender, primariamente, à divulgação, as anotações e observações de Hipólito adquirem um caráter de ensaio sociológico avant la lettre, possuindo todos os requisitos literários para figurar como obra fundadora do americanismo brasileiro, e quiçá universal. Seu diário é uma grande reportagem com desconcertantes antecipações sobre a sociedade americana e que confirma, também por antecipação, a densidade analítica e o gênio de "escrevinhador" do futuro jornalista (aliás único) do Correio Braziliense.
Lido à distância de mais de dois séculos, o Diário de Viagem de Hipólito sustenta muito bem a comparação com o bem mais cuidadosamente elaborado ensaio de Tocqueville sobre os Estados Unidos 


\section{Referências:}

COSTA, Hipólito José da. Memória sobre a viagem aos Estados Unidos, Revista do Instituto Historico e Geographico Brasileiro, Rio de Janeiro, tomo 31, 1858, p. 352-363.

Recebido em 30 de agosto de 2008 Aprovado em 25 de outubro de 2008 